\title{
Gram Titer
}

National Cancer Institute

\section{Source}

National Cancer Institute. Gram Titer. NCI Thesaurus. Code C73563.

A unit of measurement of substance concentration in a solution as determined by the quantitative reaction with added measured volume(s) of a solution of the precisely known concentration(s) of a standard reagent expressed in grams. 